\title{
PREVENÇÃO DE INFECÇÃO PRIMÁRIA DE CORRENTE SANGUÍNEA ASSOCIADA A CATETERES VENOSO CENTRAIS: UMA REVISÃO DE LITERATURA INTEGRATIVA
}

\section{ARTIGO DE REVISÃO}

BONIFÁCIO, Tatiana De Souza ${ }^{1}$

ABREU, Alcione ${ }^{2}$

BONIFÁCIO, Tatiana De Souza. ABREU, Alcione. Prevenção de infecção primária de corrente sanguínea associada a cateteres venoso centrais: Uma revisão de literatura integrativa. Revista Científica Multidisciplinar Núcleo do Conhecimento. Ano 05, Ed. 03, Vol. 10, pp. 182-201. Março de 2020. ISSN: 2448-0959, Link de acesso: https://www.nucleodoconhecimento.com.br/saude/corrente-sanguinea

\section{RESUMO}

As infecções hospitalares em UTI têm sido um dos grandes problemas no internamento hospitalar, e, nesse contexto, na utilização de cateteres tem-se percebido elevados casos de infecções. O Cateter Venoso Central (CVC) é um dos procedimentos mais utilizados em UTI e sua utilidade tem sido muito importante, uma vez que o paciente em estado crítico tem por infusão a administração de medicação, de nutrição parenteral, de fluidos intravenosos, dentre outros a fim de sua sobrevida. O CVC é um procedimento que é aplicado em diversos quadros patológicos e exemplos podem ser explicitados, como são os casos de hemodiálise, problemas cardíacos, dentre outros. Entretanto, o CVC tem sido apontado como a causa de infecções (IPCS) por via da corrente sanguínea do paciente, fato que tem gerado, por

\footnotetext{
${ }^{1}$ Enfermeira. Técnica em Enfermagem.

2 Doutorado em Enfermagem. Mestrado em Mestrado Acadêmico em Ciências do Cuidado em Saúde. Especialização em andamento em Controle de Infecção em Assistência em Saúde. Graduação em Enfermagem E Licenciatura.
} 
parte da ANVISA, normas assépticas a partir de diversos protocolos de ações. Nesse contexto, o Protocolo de Prevenção de Infecção Primária na Corrente Sanguínea do Cateter Venoso Central possui diversas ações a fins da diminuição de infecções que serão discutidas neste estudo.

Palavras-chave: Cateter Venoso Central, Protocolo de Prevenção, UTI.

\section{INTRODUÇÃO}

A Unidade de Terapia Intensiva (UTI) admite pacientes críticos que necessitam de observação constante e cuidado pormenorizado devido a sua condição clínica de alta complexidade.

As UTIs foram concebidas com a finalidade de oferecer atenção contínua e suporte avançado aos pacientes críticos, com risco de morte, lançando mão de recursos de alta tecnologia que auxiliam ou substituem a função de órgãos vitais (SANTUZZI et al, 2013, p. 418).

Essas Unidades têm como escopo principal a recuperação de pacientes em estados mais graves e, por isso, são equipadas com alta tecnologia a fim de reproduzir funções vitais dos pacientes, contando, então, com equipamentos de hemodiálise e respiradores artificiais. Um dos procedimentos mais realizado nas UTIs está relacionado ao Cateter Venoso Central (CVC). O procedimento se caracteriza pela inserção do cateter por punção via veia jugular, subclávia ou femoral, possibilitando a execução de terapias complexas no paciente. Nesse contexto, são utilizados diferentes cateteres, como: centrais, de curta ou longa permanência, semiimplantáveis e totalmente implantáveis. Embora o CVC seja um grande avanço nas UTIs, eles também são portadores de um grave problema neste cenário.

A infecção da corrente sanguínea relacionada a cateteres é um tema de grande relevância para a prática clínica em relação à busca de melhores desfechos para o paciente e, assim, tem sido muito discutida na área da enfermagem. No mundo, profissionais expertises participam ativamente de simpósios e debates a fim de discutir 
os aspectos relacionados ao tema, sobretudo sobre medidas para reduzir os números alarmantes desse tipo de infecção (DALLÉ et al, 2012). Um estudo em Michigan evidenciou como já foi possível reduzir as taxas de IPCS associadas à CVC com a aplicação de um conjunto de cinco medidas baseadas em evidências (bundle) (DALLÉ et al, 2012). Essas medidas visam à antissepsia da pele além de mecanismos de barreiras.

Nesse contexto, segundo Dallé et al (2012), o uso de clorexidina alcoólica para antissepsia do sítio de inserção, o uso de barreira máxima estéril de proteção durante a inserção, a seleção da veia subclávia como sítio ideal de inserção e a revisão diária da necessidade de manutenção do CVC são as recomendações que devem ser seguidas. Segundo Silva (2016, p. 23), "estudos demonstram que um pacote de medidas preventivas, com reforço no uso de técnica asséptica durante a inserção e manutenção de acessos vasculares, tem reduzido às infecções" Em concordância com o estudo citado, na Tailândia foi realizada uma pesquisa que apontou que a adoção de boas práticas levou a redução das taxas de infecção relacionadas ao CVC com a aplicação do bundle para inserção e medidas de manutenção dos CVCs, como, por exemplo, a padronização das trocas de coberturas de sítio e maior adesão à higienização de mãos (DALLÉ et al, 2012).

No Brasil, a discussão sobre o tema também é uma realidade. O Hospital de Clínicas de Porto Alegre (HCPA) desde 2008 tem utilizado regras contra possíveis infecções hospitalares e o hospital de referência adotou a vigilância de infecções relacionadas a CVC. Neste contexto, segundo Dallé et al(2012, p. 11), "foi verificada uma tendência de aumento dessas infecções, o que desencadeou a necessidade de levantar as possíveis razões e definir medidas de prevenção". Ainda no Brasil, a Agência Nacional de Vigilância Sanitária (ANVISA), diante dos dados estatísticos que apontam o número significante de infecções nas UTIs, tem buscado um maior rigor no cumprimento de boas práticas no que se refere aos serviços, ambientes e insumos, o que, naturalmente, envolve as UTIs.

Existem legislações e diretrizes direcionadas a diminuir os quadros infecciosos. Dentre as recomendações vigentes, as precauções máximas em relação às barreiras 
que buscam isolamentos a partir de insumos preveem que gorros e máscaras deverão ser utilizados pela equipe de saúde (DALLÉ et al, 2012). A implementação do protocolo de prevenção de infecção primária de corrente sanguínea associada ao CVC tem sido um dos procedimentos hospitalares mais relacionados nos casos de infecções, portanto, deve levar-nos a uma maior preocupação e conscientização de sua aplicabilidade. Por isso, o objeto de estudo dessa pesquisa é a implementação por enfermeiros do protocolo de prevenção de infecção primária de corrente sanguínea associado a cateteres venosos centrais para a prevenção de eventos adversos (GOTTSCHALL, 2009).

A aplicabilidade dos procedimentos protocolares quanto à inserção do CVC envolve técnicas assépticas, atenção quanto à infusão de soluções, curativos adequados, utilização restrita de conexões em $\mathrm{Y}$ além da perspicácia às possíveis reações exteriorizadas, por exemplo, por pacientes transplantados e imunodeprimidos, melindrosos a infecção serão sempre as armas mais simples e eficazes na profilaxia da infecção de corrente sanguínea (ANVISA, 2017). Nesse contexto, grande parte das IPCS pode ser prevenida por meio de programas que enfocam na educação continuada, na capacitação dos profissionais de saúde, na adesão às recomendações durante a inserção e no manuseio dos cateteres (ANVISA, 2017). Isso demonstra a importância do cumprimento pormenorizado do protocolo de prevenção e sua estreita relação com o cuidado de Enfermagem, uma vez que, ao cumpri-los, os resultados são profícuos.

Traçamos como objetivo analisar as evidências científicas brasileiras mais recentes sobre a atuação do enfermeiro na implementação do protocolo de prevenção de infecção primária de corrente sanguínea associado a cateteres venosos centrais para a prevenção de eventos adversos. Ao agruparmos e analisarmos as melhores e mais recentes evidências relacionadas ao tema, acreditamos que o estudo pode contribuir para com um cuidado de Enfermagem de mais qualidade, possibilitando melhores desfechos aos pacientes, reduzindo custos relacionados aos quadros infecciosos para as Instituições de saúde além de acreditarmos que o estudo pode colaborar para com 
o ensino e com a pesquisa de enfermagem à medida que amplia o acervo bibliográfico para pesquisa na área.

\subsection{OBJETIVOS}

\subsubsection{OBJETIVO GERAL}

Realizar uma revisão de literatura com base nos artigos já publicados que discutem sobre a utilização de cateteres em diversos procedimentos de ordem fisiológica e terapêutica e com base em diagnósticos, agregando, nesse processo, recursos de imagens e fármacos.

\subsubsection{OBJETIVO ESPECÍFICO}

Descrever os cuidados quanto aos procedimentos do Bundle do CVC a fim de combater possíveis infecções.

\subsection{JUSTIFICATIVA}

A importância do cateter possibilita diversos procedimentos de ordem fisiológica e terapêutica assim como diagnósticos agregados à recursos de imagens e fármacos (GOTTSCHALL, 2009). O uso especializado do cateter deve ser profícuo ao processo do paciente, uma vez que devem ser considerados os riscos no procedimento pelo profissional da saúde. Portanto, a complexidade do CVC exige, dentre muitos aspectos, o conhecimento técnico apropriado além da experiência procedimental do profissional da saúde. Verifica-se que o CVC de Curta Permanência tem sua inserção nos vasos centrais, ou seja, na subclávia, jugular e femoral por meio da venopunção direita e, por não serem tunelizados, não previnem traumas de repetidas punções quando há necessidade de acesso central por curto período, por exemplo.

Já o CVC Longa Permanência semi-implantado perpassa por via central um túnel subcutâneo, permitindo, então, a exteriorização parcial do cateter onde sua porção é tunelizada (GOTTSCHALL, 2009). O cateter apresenta um material poroso e biocompatível, idealizado para promover maior aderência de fibrina, ocluindo o túnel 
à entrada de patógenos e propiciando maior fixação do mesmo no tecido subcutâneo (PACHECO et al, 2015). O cateter de longa permanência já possui seu acesso por meio de punção com agulha, o que compreendemos ser muito relevante quanto ao seu infortúnio ao paciente, e, assim, a utilização deverá ser previamente calculada pelo enfermeiro (PACHECO et al, 2015).

\section{REVISÃO DE LITERATURA}

Diante de quadros mais graves aos pacientes provocados por diversas patologias, exige-se maiores cuidados médicos emergenciais. Nesse contexto, a UTI - Unidade de Terapia Intensiva constitui-se no escopo de preencher esta lacuna na área hospitalar, e, assim, ações mais urgentes são necessárias (DALLÉ et al, 2012). Assim sendo, o presente artigo busca apontar aspectos relacionados à Unidade de Terapia Intensiva em atendimento e procedimento CVC - Cateter Venoso Central ao público/paciente adulto, não desconsiderando seu papel, por exemplo, pediátrico, como exemplificaremos na presente pesquisa.

Importa-nos apontar que a era chamada digital e tecnológica tem desde, principalmente, o século XX contribuído para com ambientes que comportam a UTI, e, assim, esse espaço tem ajudado, portanto, na sobrevida dos pacientes internados nas Unidades de Terapia Intensiva. Uma dessas ferramentas tecnológicas mais presentes na atualidade é o cateter. Esse instrumento tem sido utilizado desde anos 40, isto é, desde o século XX. Sua eficiência é inegável, uma vez que sendo um instrumento intravascular possibilita o acesso profícuo imediato à corrente sanguínea do paciente. Por exemplo, na área cardiovascular:

Cateteres diagnósticos visam três propósitos principais: medir variáveis hemodinâmicas e vasculares; recolher amostras de sangue para análise; e injetar contraste intravascular. Cateteres terapêuticos servem para injetar fluidos ou drogas, dilatar vasos ou fechara defeitos com dispositivos adicionados a eles, e liberar objeto estranho nos vasos, por exemplo, stent (GOTTSCHALL, 2009, p. 247). 
Nota-se a importância do uso do cateter, uma vez que possibilita diversos procedimentos de ordem fisiológica e terapêutica assim como diagnósticos agregados à recursos de imagens e fármacos de maneira profícua ao profissional da saúde e ao paciente a partir de ações intervencionistas, o que compreendemos ser bem significante. Em contra partida, pode-se perceber que o CVC tem apresentado vários riscos quanto ao seu procedimento (GOTTSCHALL, 2009). O presente artigo destaca, categoricamente, que riscos na instrumentalização do CVC devem-se devido à inadequação de ações, por exemplo, da inserção do CVC além de questões relativas à manutenção de instrumentos. Esses fatores são otimizadores quanto aos quadros de infecções no processo de referência, e, dessa forma, a proficiência da equipe de enfermagem, por exemplo, é insubstituível e fundamental para o sucesso da intervenção médico-hospitalar.

A manipulação bem-sucedida do cateter exige boa coordenação motora, que melhora com a experiência; o conhecimento vascular; e uma estimativa de como fios-guia e cateteres específicos se movem sozinhos e um em relação ao outro. Os cateteres em geral devem ser avançados por um fio-guia a fim de evitar a lesão do vaso, mas certos formatos de cateteres são traumáticos quando avançam e podem ser removidos sem um fio-guia. $O$ formato do cateter pode ajudar a selecionar a origem de um vaso ou transpor uma lesão complexa em conjunto com um fio-guia de ponta reta ou curva (CHRIKF; CAMBRIA, 2016, p. 46).

Portanto, os riscos devem ser considerados pelo profissional da saúde além da perspicácia instrumentar, pois ocorre, por exemplo, a diversidade de cateteres, e, em alguns casos, o mesmo instrumento não é capaz de realizar todo procedimento.

A troca cuidadosa por um cateter de curvatura simples pode facilitar o cateterismo de vasos-alvo mais distais e o acompanhamento de um cateter-guia na artéria carótida comum. Embora um cateter de curvatura complexa possa facilitar o cateterismo de origem de um vaso, a dirigibilidade pode ser comprometida, se comparada com a dos cateteres retos e de curvatura simples (CHRIKF; CAMBRIA, 2016, p. 46). 
Nota-se, portanto, a complexidade do CVC, o que exige o conhecimento técnico apropriado e experiência procedimental do profissional da saúde. Nesse sentido, o procedimento do CVC está presente, também, em UTIs pediátricos, entretanto não é o escopo do presente artigo. O sucesso do procedimento CVC na UTI pode ser percebido também na Neonatologia a partir da terapia intravenosa, uma vez que exige a: "administração de drogas vasoativas, hiperosmolares, antibióticos e nutrição parenteral [que] exige a manutenção de um acesso venoso seguro e duradouro" (Macêdo et al, 2011, p. 42). Embora o presente artigo tenha como êxito o paciente adulto, acreditamos que, a fins empíricos, seja válida a abordagem do procedimento CVC também ao paciente infantil.

Portanto, embora haja entraves quanto o procedimento do CVC na UTI, por exemplo, em pacientes adultos, é historicamente comprovado a importância do procedimento hospitalar de referência. Neste viés, insistimos que a proficiência da equipe de enfermagem agregada ao espaço hospitalar de internamento profícuo, à sistematização de procedimentos $\mathrm{e}$ às medidas preventivas são componentes/aspectos basilares ao êxito do procedimento CVC na UTI (OLIVEIRA, 2016). Compreendemos por nevrálgico a presença infecciosa no paciente em Terapia Intensiva. Tal ruído hospitalar tem sido percebido significantemente no contexto de referência, cujos diversos tratados são construídos a fim de explicar e resolver os possíveis entraves hospitalares do procedimento.

Nessa perspectiva, nota-se que a punção venosa central ou profunda é um procedimento comumente utilizado em pacientes críticos, os quais necessitam de vigilância intensiva e apresentam alta complexidade, e, portanto, muito cuidado pelo profissional de saúde. Como instrumentalização hospitalar, o cateter venoso central (CVC) é um dispositivo intravenoso usado na soroterapia, administração de medicamentos, infusão de derivados sanguíneos, monitorização hemodinâmica, nutrição parenteral, terapia renal substitutiva, dentre outros (OLIVEIRA, 2016). Ele evita a punção venosa de repetição, preservando a integridade venosa, pois o CVC pode permanecer por vários dias no paciente. Assim, notamos que há um número significativo em relação à presença de infecções relacionadas, por exemplo, na 
corrente sanguínea, uma vez que é notória a funesta presença de cepas bacterianas multirresistentes em ambientes hospitalares (OLIVEIRA, 2016).

\subsection{TIPOS DE CATETERES}

Em um primeiro momento estamos diante de um procedimento cirúrgico, o que envolve normas assépticas, a não ser em situações de extrema emergência. Quanto ao procedimento literal do CVC, compreendemos a importância da escolha da cúpula pleural direita, eliminando alguns riscos de pneumotórax na punção subclávia. Devese, também, observar-se que a questão do trajeto em linha reta diminuirá o mau posicionamento do cateter, por exemplo, na jugular interna. Quanto aos tipos de CVC existem os de Curta Permanência, Longa Permanência - totalmente implantado, Longa Permanência semi-implantado e de Inserção Periférica. O CVC de Curta Permanência tem sua inserção nos vasos centrais, ou seja, na subclávia, jugular e femoral por via da venopunção direita, e, por não serem tunelizados, não previnem traumas de repetidas punções.

De acordo com Silva, (2016, p. 20 apud AVISA, 2010) são "frequentemente empregados quando há necessidade de acesso central por curtos períodos, tipicamente entre 10 e 14 dias, de onde deriva sua denominação". O CVC de Longa Permanência - totalmente implantado, conforme sugere a nomenclatura, o instrumento siliconado ou por meio de poliuretano tem a sua implantação cirurgicamente e não permite exteriorizações após o procedimento de referência. Ainda de acordo com Silva (2016, p. 20 apud AVISA, 2010), "os cateteres de longa permanência têm como ponto inconveniente o seu acesso através de punção com agulha - ponto relevante de possível desequilíbrio, que deve ser previamente avaliado pelo enfermeiro". O CVC Longa Permanência semi-implantado perpassa por via central um túnel subcutâneo, permitindo, então, a exteriorização parcial do cateter.

Na sua porção tunelizada, o cateter apresenta uma "manga" ou "bainha", também chamada de cuff, de dacron, em material poroso e biocompatível, idealizado para promover maior aderência de fibrina, ocluindo o túnel à entrada de patógenos e propiciando maior fixação do 
mesmo no tecido subcutâneo. Seus modelos, apresentações, comprimentos, bem como algum dispositivo adicional, tipo válvula bidirecional em sua ponta proximal ou distal e diferenciação das vias por códigos de cores, variam de acordo com a empresa fabricante. São constituídos de material flexível e radiopaco, podendo ser de silicone, poliuretano ou de teflon. Apresentam-se com uma, duas ou três vias, independentes entre si, de comprimentos e calibres variados (SILVS, 2016, p. 22 apud INCA, 2008).

A utilização do CVC de Longa Permanência semi-implantado tem seus maiores agravos por: infecção, extravasamento, obstrução, dentre outros aspectos. O CVC por Inserção Periférica, como os demais apontados na presente pesquisa, compreende que a inserção periférica é significante no tratamento em UTIs. Também exige extremos cuidados por parte do profissional da saúde, em particular o enfermeiro (a). O CCIP ou PICC, que se caracteriza por construção siliconada ou em poliuretano, varia quanto ao seu comprimento, entre 10 e $75 \mathrm{~cm}$, revela algumas particularidades benéficas em meio um processo nevrálgico, como:

Menor custo; menores riscos relacionados ao cateter; dispensa a utilização de sala cirúrgica, podendo ser inserido em qualquer local, inclusive no leito de internação ou em residências; exige apenas um $\mathrm{RX}$ simples para confirmação de sua localização após ser inserido. Os CCIPs são indicados, inicialmente, para tratamento quimioterápico de até um ano de duração prevista. Sua indicação está associada à necessidade de acesso venoso central e às boas condições venosas periféricas do paciente. Outras indicações, segundo a comissão interdisciplinar de cateteres, são para pacientes de suporte terapêutico, inclusive em terapia domiciliar, tanto para a instalação, quanto para manutenção (SILVA, 2016, p. 23 apud INCA, 2008).

Apenas quando o paciente não possui uma rede venosa periférica propícia é que o referente paciente fica impedido do CVC por Inserção Periférica. 


\subsection{PROTOCOLOS DE IPCS}

Considerando o contexto apresentado, a partir da literatura, tem-se percebido que os agentes infecciosos (micro-organismos) têm se revelado como mais resistentes, e, assim, acabaram se multiplicando, mesmo com ações antimicrobianas e terapêuticas, o que acaba gerando uma estadia maior do paciente hospitalar. De acordo com Brasil (2010), dentre as infecções relacionadas à assistência à saúde (IRAS), temos as Infecções Primárias de Correntes Sanguíneas (IPCS), que se destacam por estarem entre as mais ocorridas em pacientes com cateter venoso central. Esta infecção está diretamente associada às altas taxas de mortalidade ou ao maior tempo de internação, o que também gera maiores gastos.

Portanto, considera-se que mais da metade das infecções de referência estão claramente relacionadas ao uso de dispositivo intravascular, o que compreendemos ser um número alto. Mas, como já temos destacado no presente artigo, isso se deve, principalmente, à inadequação do procedimento CVC. Quanto aos protocolos de IPCS, estão institucionalizados com fins de medidas preventivas, e, portanto, de controle de infecção de ordem primária na corrente sanguínea. Tais medidas estão agrupadas em ações de inserção e instrumentalização do CVC propriamente dito além de contemplar ações higienistas, o que envolve, também, o ambiente hospitalar. Assim, a leitura simples dos protocolos de referência leva-nos à compreensão de que:

A cateterização venosa central, deve ser observadas as seguintes recomendações: escolha do sítio de inserção do cateter onde o risco de infecção seja menor e que este possa ser seguramente inserido; higienização das mãos com água e sabonete líquido ou preparação alcoólica, antes de iniciar o procedimento; utilização de barreira máxima de precaução através do uso de máscara, touca, avental e luvas estéreis quando for inserir o dispositivo (SILVA, 2016, p. 24).

Não somente a equipe de enfermagem e os instrumentos devem seguir os protocolos, mas também o ambiente físico e o próprio paciente, por exemplo, quanto à pele do paciente a partir de componentes antissépticos. Todos esses aspectos de referência 
são importantes, e, portanto, devem ser observados pormenorizadamente quanto à utilização do cateter. Nessa perspectiva, compreendemos que a equipe de enfermagem, como, por exemplo, os executores da Comissão de Controle de Infecção Hospitalar $(\mathrm{CClH})$, possuem o papel de fornecer subsídios como informações e atualizações sobre métodos e técnicas de prevenção de contaminação cruzada, vigilância epidemiológica, sistema de notificação, providência de protocolos e padronização de rotinas (Portaria № 2616 de 1981).

Compreendemos a importância da Unidade de Terapia Intensiva por envolver, por exemplo, uma maior imprescindibilidade aos pacientes internados além de maior especialização da instrumentalidade da equipe de enfermagem, o que demanda treinamento qualificado, e, portanto, melhor profissionalismo. O presente artigo acentua a necessidade cada vez maior de melhorias das unidades de referência além de cuidados acentuados pela equipe de enfermagem, uma vez que é evidente os problemas infecciosos, por exemplo, quanto às infecções relacionadas as correntes sanguíneas, em especial ao procedimento Cateter Venoso Central, que é a temática do presente artigo. Nota-se que o procedimento de referência é bastante comum em Unidades de Terapia Intensiva cujas drogas vasoativas são infundidas no paciente.

Tem-se como objetivo a monitorização hemodinâmica, nutrição parenteral, marcapasso transvenoso, infusão de quimioterápicos, hemodiálise e impossibilidades de acesso periférico. Segundo Pedrolo et al (2011), apesar de serem amplamente utilizados, esses dispositivos expõem o cliente a complicações, tais como infecção da corrente sanguínea, trombose, pneumotórax, dentre outras. Portanto, deparamos com possibilidades de agravamento do estado clínico do paciente e até mesmo com o óbito. Também notamos que quando não ocorre o óbito o paciente acaba precisando de uma maior permanência no ambiente hospitalar, gerando, além do desconforto e sofrimento do paciente, custos financeiros mais elevados.

Assim sendo, é preciso que compreendamos que os fatores destacados como referência implicam na necessidade de enfatizar a labuta quanto à inquestionável rigidez nos procedimentos diversos que englobam e fazem parte da rotina da equipe hospitalar, em particular do cotidiano dos profissionais que pertencem à equipe de 
enfermagem. O CVC se caracteriza por possibilitar a estabilização no paciente por seu procedimento, pois, por exemplo, ocorre a movimentação de microrganismos via corrente sanguínea do paciente, e, assim, deparamos com dois dispositivos basilares: as colonizações extraluminal e intraluminal. Sobre Colonização extraluminal e intraluminal, essa se caracteriza por:

Microrganismos contaminantes da pele, provavelmente auxiliados por ação da capilaridade, penetram através da pele durante a inserção do cateter ou nos dias que se seguem após a inserção. Colonização intraluminal: migração do patógeno pela corrente sanguínea, por infecções originárias em outro local, como pneumonia, ou, ainda, a infusão de soluções contaminadas. A entrada dos microrganismos pode acontecer pelo canhão (hub) do cateter, ou pelo seu lúmen, através do guia utilizado durante a inserção do cateter, ou durante a manipulação do cateter, ou dos conectores com as linhas de infusão, ou pela administração de soluções intravenosas (Pedroso et al, 2011, p. 470).

Nos deparamos com algumas possibilidades de contaminações relacionadas à destreza dos microrganismos que ficam na superfície do tubo. Uma vez se alojando na parte externa do cateter, as bactérias velozmente se reproduzem formando uma estrutura significante. Compreendemos que quanto maior o tempo de permanência do CVC no paciente, maiores são os riscos de infecções, sobretudo quando os preventivos não são pormenorizadamente observados. O mercado oferece várias opções quanto, por exemplo, esses preventivos. De acordo com Pedroso et al (2011, p. 280): "existem diferentes curativos no mercado, sendo que o gaze e fita e o filme transparente de poliuretano são mais utilizados". Portanto, são recursos indispensáveis e de fácil aplicação, e, assim, são preventivos em relação aos processos inflamatórios no paciente.

\subsection{BUNDLE DO CVC}

Bundle está relacionado às boas práticas no contexto hospitalar, o que se agrega a Unidade de Terapia Intensiva de pacientes, como é o caso dos adultos. Uma equipe 
de enfermagem bem organizada, capacitada tecnicamente, e, portanto, atenta as boas práticas hospitalares, resultará em uma proficiência profissional profícua. Quanto à inserção a inserção do cateter:

O bundle de inserção de CVCs incluiu os itens: higienização das mãos pelo médico e pelo auxiliar do procedimento com clorexidina degermante antes da passagem de CVC; antissepsia do sítio de inserção do CVC com friç̧ão com clorexidina alcoólica 0,5\%; secagem da pele após friç̧ão com clorexidina alcoólica (20 segundos); uso de métodos de barreira máxima (luva estéril, campo estéril, avental estéril, máscara e touca) pelo médico e pelo auxiliar do procedimento; preferência pela veia subclávia como sítio ideal de inserção e, no caso do cateter de hemodiálise de curta permanência, preferência pela veia jugular como sítio de inserção (DALLÉ et al, 2012, p. 11).

Além dos componentes de referência, existe a manutenção diária de todo o processo hospitalar que envolve os cuidados relacionados as boas práticas funcional do profissional hospitalar, o que se exige:

Higienização das mãos antes da manipulação do CVC; desinfecção dos hubs e conexões com álcool a 70\% antes do manuseio do CVC; registro da troca de cobertura do sítio do cateter com clorexidina alcoólica $0,5 \%$ (a cada 48 horas para coberturas com gaze e a cada sete dias para coberturas transparentes); e registro com a descrição da inserção do sítio do cateter na evolução de enfermagem diária dos pacientes (DALLÉ et al, 2012, p. 11).

Quanto ao uso do CVC, o Bundle tem se revelado importante, já que tem apresentado diminuição nos casos de infecção nas UTIs, uma vez que suas medidas de prevenção possibilitam uma diminuição significativa em infecções em UTIs, o que exige o cuidado constante pormenorizado pelas equipes de enfermagem, antes, durante e após os procedimentos de CVC nas UTIs. Assim sendo, pensamos que os cuidados quanto aos procedimentos do Bundle do CVC precisam ser sistemáticos a fim da manutenção 
eficaz do processo quanto à sua principal função: eliminar os riscos de infecções no CVC. Os Checklists parecem-nos um instrumento de aferição e controle profícuo ao processo de referência, uma vez que poderá controlar a entrada e saída dos procedimentos, por exemplo, hospitalares nas UTIs (DALLÉ et al, 2012).

Deve-se observar o exercício da construção sempre do Checklist como documento nas UTIs no CVC, e, assim, deverá ser flexível quanto às novas recomendações necessárias. Esses detalhes auxiliarão no aprimoramento instrumental/operacional de funções hospitalares e sinalizarão a evolução das melhorias sugeridas pelo Bundle (DALLÉ et al, 2012). Esses preventivos são profícuos em qualquer intervenção cirúrgica, uma vez que possuem o escopo preventivo de infecções hospitalares. Destacamos que as Precauções Máximas de Barreiras em particular por se tratar de prolegômenos aos procedimentos de CVC nas UTIs. Também acreditamos que esses preventivos deverão se exteriorizar em interações mútuas, e, portanto, como ideário inter e multidisciplinar, de forma a agregar ações assépticas e técnicas de prevenções por parte de diversos profissionais em relação ao uso dos CVC nas UTIs.

\section{METODOLOGIA}

Trata-se de uma revisão integrativa da literatura baseada em artigos publicados nos últimos 10 anos e utilizou-se como base de dados a Scientific Electronic Library Online (SCIELO) e a Literatura Latino-Americana e do Caribe em Ciências da Saúde (LILACS). A busca foi realizada de setembro de 2018 a maio de 2019. Foi utilizada a estratégia de PICO: População/Paciente $(\mathrm{P})$ : pacientes internados em UTIs; Intervenção (I): Protocolo de prevenção de infecção primária de corrente sanguínea associada a cateteres venosos centrais; Comparação (C): não há e Desfecho/Outcome $(\mathrm{O})$ : prevenção de infecção primária de corrente sanguínea associada a cateteres venosos centrais a partir da aplicação de Protocolo de Prevenção. Considerou-se como pergunta de pesquisa: "como os enfermeiros da Terapia Intensiva (UTIs) poderão prevenir infecção primária de corrente sanguínea (IPC) associada a cateteres venosos centrais (CVC) através da aplicação de bundles?" 


\subsection{INCLUSÃO}

Delimitou-se como critério de inclusão artigos na íntegra, em língua portuguesa, publicados entre 2000 e 2017e pesquisas aplicadas à pacientes adultos internados em UTIs que foram submetidos à implantação de CVC.

\subsection{EXCLUSÃO}

Os critérios de exclusão utilizados na pesquisa foram: estudos que não disponibilizaram o texto na íntegra, sem aderência ao objeto de estudo e que abordaram pacientes pediátricos.

\subsection{DESCRITORES}

Os descritores selecionados que se encontram disponíveis no Portal dos Descritores em Ciência da Saúde (Decs) foram: assepsia, protocolos, unidades de terapia intensiva (UTI), cateter venoso central (CVC), pacientes internados e infecção. Foram combinados da seguinte forma: assepsia e infecção; unidade de terapia intensiva (UTI) e pacientes internados; cateteres venosos centrais (CVC) e protocolo. Após leitura criteriosa dos resumos e dos textos na íntegra, os estudos foram organizados e sumarizados em uma tabela por meio do software Microsoft Word 2013 que contou com as seguintes variáveis: título, período e ano de publicação, autores, desenho do estudo e resultados/desfecho. Após o levantamento realizado para o desenvolvimento do estudo, foram selecionados 08 artigos, conforme a figura 1. 
Figura 1: Resultados

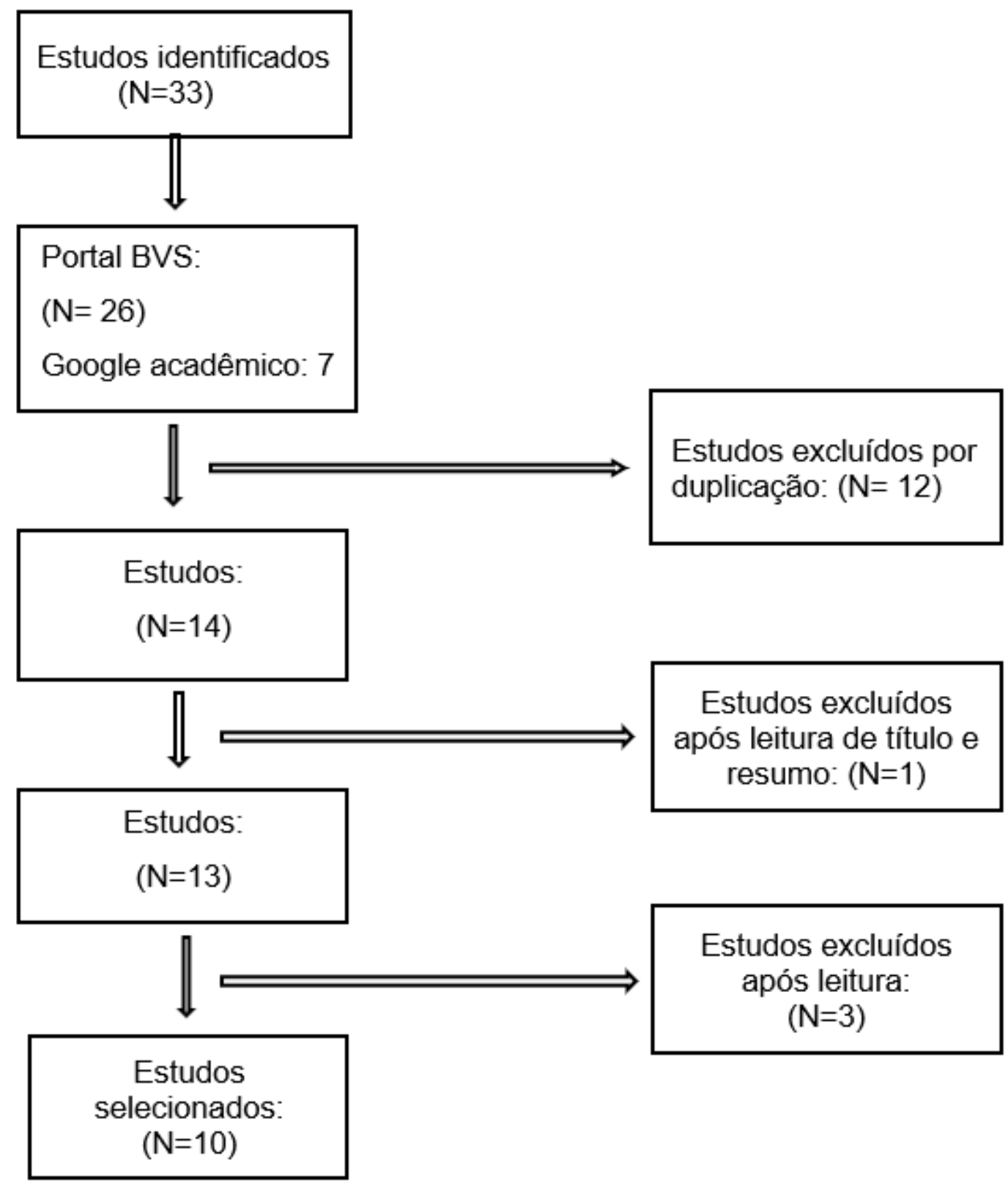

Fonte: Elaborado pela autora (2020)

Os artigos selecionados para o presente artigo foram todos publicados no Brasil entre os anos de 2009 a 2017, sendo três artigos escritos em 2009, um artigo em 2011, dois artigos em 2012, um artigo em 2015, dois artigos em 2016 e um artigo em 2017. Considerando esses artigos de referência, notou-se que, em relação à temática proposta, a região Sul destaca-se com oito artigos, sendo três em Porto RC: 47763

Disponível em: https://www.nucleodoconhecimento.com.br/saude/corrente-sanguinea 
Alegre (RS), três no Paraná (RS) e dois em Curitiba (PR). Prosseguindo, há um na região Centro-Oeste, em Brasília (DF) e um na região Sudeste, no Rio de Janeiro (RJ). Quanto às pesquisas realizadas para a elaboração dos artigos, foi observado que sete artigos realizaram as pesquisas em hospitais privados e públicos (SUS) e, também, em hospitais universitários. Um artigo realizou a pesquisa a partir de base de dados.

Quadro 1 - Distribuição dos artigos selecionados, 2000 a 2017, RJ, Brasil

\begin{tabular}{|c|c|c|c|c|}
\hline TÍTULO & PERIÓDICO & AUTORES & DELINEAMENTO & RESULTADOS \\
\hline $\begin{array}{c}\text { Neonatology } \\
\text { nurses' knowledge } \\
\text { about Peripherally } \\
\text { Inserted Central } \\
\text { Venous Catheter. }\end{array}$ & $\begin{array}{c}\text { Revista Brasileira } \\
\text { de Enfermagem/2012 }\end{array}$ & BELO, Marcela et al. & $\begin{array}{c}\text { Descritivo, } \\
\text { transversal, com } \\
\text { abordagem } \\
\text { quantitativa. }\end{array}$ & $\begin{array}{c}\text { O artigo analisa } \\
\text { o conhecimento } \\
\text { e a prática dos } \\
\text { enfermeiros } \\
\text { acerca da } \\
\text { utilização } \\
\text { do Cateter } \\
\text { Central de } \\
\text { Inserção Periféri } \\
\text { ca }\end{array}$ \\
\hline \begin{tabular}{|c|} 
Comportamento \\
da \\
equipe multiprofis \\
sional Frente \\
ao Bundle Do Cate \\
ter Venoso Central \\
na Terapia \\
Intensiva.
\end{tabular} & $\begin{array}{l}\text { Escola Anna } \\
\text { Nery } / 2016\end{array}$ & $\begin{array}{c}\text { OLIVEIRA, Francim } \\
\text { ar et al. }\end{array}$ & Exploratório & $\begin{array}{c}\text { O artigo } \\
\text { analisa o } \\
\text { comportamento } \\
\text { das equipes de } \\
\text { enfermagem e } \\
\text { médica } \\
\text { relacionada ao } \\
\text { Bundle de } \\
\text { inserção e às } \\
\text { boas práticas no } \\
\text { manejo do } \\
\text { Cateter Venoso } \\
\text { Central. }\end{array}$ \\
\hline $\begin{array}{c}\text { Infecção } \\
\text { relacionada a CVC } \\
\text { após a } \\
\text { implementação de } \\
\text { um conjunto de } \\
\text { medidas } \\
\text { preventivas } \\
\text { (bundle) no centro } \\
\text { de terapia } \\
\text { intensiva (CTI) do } \\
\text { Hospital de } \\
\text { Clínicas de Porto } \\
\text { Alegre. }\end{array}$ & Revista HCPA/2012 & $\begin{array}{l}\text { DALLÉ, Jessica; } \\
\text { DOS, Santos; } \\
\text { MORA, Kuplich; } \\
\text { TOLFO, Silveira. }\end{array}$ & Experimental & \begin{tabular}{|c|} 
O artigo apontou \\
uma oscilação na \\
taxa de adesão \\
ao bundle de \\
inserção, em \\
contrapartida \\
apontou uma \\
melhora na \\
adesão \\
ao bundle de \\
manutenção.
\end{tabular} \\
\hline
\end{tabular}




\begin{tabular}{|c|c|c|c|c|}
\hline $\begin{array}{l}\text { 1929-2009: } 80 \\
\text { Anos de } \\
\text { cateterismo } \\
\text { cardíaco - uma } \\
\text { história dentro da } \\
\text { história. }\end{array}$ & $\begin{array}{l}\text { Revista Brasileira } \\
\text { de Cardiologia Invas } \\
\text { iva/2009 }\end{array}$ & $\begin{array}{l}\text { GOTTSCHALL, } \\
\text { Carlos }\end{array}$ & Investigativo & $\begin{array}{c}\text { O } \\
\text { artigo aponta o } \\
\text { desenvolvimento } \\
\text { da ideia de } \\
\text { angioplastia tran } \\
\text { sluminal periféri } \\
\text { ca e } \\
\text { coronariana, e as } \\
\text { conquistas } \\
\text { fundamentais, } \\
\text { como os stents, } \\
\text { que permitiram o } \\
\text { extraordinário } \\
\text { progresso desse } \\
\text { procedimento, } \\
\text { que tem } \\
\text { dominado a } \\
\text { cardiologia } \\
\text { intervencionista. }\end{array}$ \\
\hline $\begin{array}{c}\text { Dimensionament } \\
\text { o da equipe de } \\
\text { enfermagem da } \\
\text { UTI-adulto de } \\
\text { um hospital de } \\
\text { ensino }\end{array}$ & $\begin{array}{c}\text { Revista Eletrônica de } \\
\text { Enfermagem } / 2009\end{array}$ & $\begin{array}{l}\text { INOUE, Kelly. } \\
\text { MATSUDA, Laura }\end{array}$ & $\begin{array}{l}\text { Descritivo- } \\
\text { exploratório }\end{array}$ & $\begin{array}{c}\text { Este estudo } \\
\text { possibilitou } \\
\text { verificar a } \\
\text { adequação } \\
\text { quantitativa } \\
\text { do pessoal } \\
\text { de } \\
\text { enfermage } \\
\text { m da UTI- } \\
\text { A de um } \\
\text { Hospital } \\
\text { Ensino aos } \\
\text { critérios } \\
\text { estabelecid } \\
\text { os pela } \\
\text { Resolução } \\
\text { COFEN n } \\
293 / 2004 .\end{array}$ \\
\hline
\end{tabular}




\begin{tabular}{|c|c|c|c|c|}
\hline $\begin{array}{l}\text { Ensaio clínico } \\
\text { controlado sobre } \\
\text { o curativo de } \\
\text { cateter venoso } \\
\text { central. }\end{array}$ & $\begin{array}{c}\text { Acta Paulista de } \\
\text { Enfermagem/2011 }\end{array}$ & $\begin{array}{c}\text { PEDROLO, Edvane } \\
\text { et al. }\end{array}$ & $\begin{array}{l}\text { Ensaio clínico } \\
\text { controlado } \\
\text { randomizado }\end{array}$ & \begin{tabular}{|c} 
O artigo aponta \\
que o tipo de \\
curativo não \\
diminui a \\
incidência \\
de infecção \\
relacionada \\
ao cateter, a \\
capacidade \\
de fixação é \\
semelhante, \\
o \\
curativo de g \\
aze e fita \\
possui \\
capacidade \\
de absorção \\
de exsudato, \\
porém \\
apresenta \\
probabilidad \\
e maior de \\
desenvolver \\
reação local.
\end{tabular} \\
\hline $\begin{array}{l}\text { Conhecimento do } \\
\text { Enfermeiro em } \\
\text { relação ao cateter } \\
\text { totalmente } \\
\text { implantado. }\end{array}$ & $\begin{array}{c}\text { Journal of Health } \\
\text { Sciences, v. 16, n. 3, } \\
2015 .\end{array}$ & $\begin{array}{l}\text { PACHECO, Giovana } \\
\text { Cristine et al. }\end{array}$ & $\begin{array}{l}\text { quisa descritiva com } \\
\text { análise quantitativa. }\end{array}$ & $\begin{array}{c}\text { Percebeu-se que } \\
\text { a maior parte } \\
\text { dos } \\
\text { enfermeiros } \\
\text { não está em } \\
\text { condições de } \\
\text { desenvolver } \\
\text { cuidados } \\
\text { com este } \\
\text { tipo de } \\
\text { cateter. }\end{array}$ \\
\hline $\begin{array}{l}\text { Infecção de } \\
\text { cateter vascular } \\
\text { central em } \\
\text { pacientes } \\
\text { adultos de um } \\
\text { centro de } \\
\text { terapia } \\
\text { intensiva. }\end{array}$ & $\begin{array}{l}\text { Revista Gaúcha de } \\
\text { Enfermagem } / 2009\end{array}$ & $\begin{array}{l}\text { MARQUES, } \\
\text { Netto et al. }\end{array}$ & $\begin{array}{l}\text { Estudo Descritivo } \\
\text { Retrospectivo }\end{array}$ & $\begin{array}{l}\text { O artigo apontou } \\
\text { que a incidência } \\
\text { da infecção na } \\
\text { utilização de } \\
\text { CVC pode estar } \\
\text { associada à } \\
\text { complexidade } \\
\text { das condições } \\
\text { clínicas e à } \\
\text { suscetibilidade } \\
\text { dos pacientes de } \\
\text { CTI durante a } \\
\text { internação. }\end{array}$ \\
\hline
\end{tabular}




\begin{tabular}{|c|c|c|c|c|}
\hline $\begin{array}{l}\text { Aspectos éticos e } \\
\text { humanizados da } \\
\text { fisioterapia na } \\
\text { UTI: uma } \\
\text { revisão } \\
\text { sistemática. }\end{array}$ & $\begin{array}{c}\text { Fisioterapia em } \\
\text { Movimento, v. 26, n. } \\
\text { 2, 2017. }\end{array}$ & $\begin{array}{l}\text { SANTUZZI, Cíntia } \\
\text { H. et al. }\end{array}$ & $\begin{array}{c}\text { Revisão } \\
\text { bibliográfica }\end{array}$ & $\begin{array}{l}\text { De acordo com } \\
\text { a revisão } \\
\text { bibliográfica } \\
\text { apresentada, } \\
\text { considera-se de } \\
\text { fundamental } \\
\text { importância o } \\
\text { envolvimento e } \\
\text { a participação } \\
\text { do } \\
\text { fisioterapeuta } \\
\text { nos debates que } \\
\text { envolvem } \\
\text { dilemas éticos } \\
\text { em UTI. }\end{array}$ \\
\hline $\begin{array}{l}\text { Comportamento } \\
\text { da equipe } \\
\text { multiprofissional } \\
\text { frente ao bundle } \\
\text { do cateter venoso } \\
\text { central na terapia } \\
\text { intensiva. }\end{array}$ & \begin{tabular}{|c} 
Escola Anna Nery \\
Revista de \\
Enfermagem, v. $20, \mathrm{n}$. \\
$1,2016$.
\end{tabular} & $\begin{array}{c}\text { TINOCO DE } \\
\text { Oliveira, Francimar } \\
\text { et al. }\end{array}$ & Questionário & $\begin{array}{l}\text { Na pré-inserção } \\
\text { do cateter há } \\
1,6 \text { mais } \\
\text { chances dos } \\
\text { procedimentos } \\
\text { de higienização } \\
\text { antisséptica das } \\
\text { mãos e opção } \\
\text { pela veia a ser } \\
\text { puncionada, } \\
\text { serem } \\
\text { questionados, } \\
\text { quando não } \\
\text { atendem as } \\
\text { recomendações } \\
\text { vigentes, se } \\
\text { forem } \\
\text { acompanhados } \\
\text { por profissional } \\
\text { de nível } \\
\text { superior. }\end{array}$ \\
\hline
\end{tabular}

Fonte: Elaborado pela autora (2020)

\section{CONSIDERAÇÕES FINAIS}

Percebemos que o CVC, embora eficiente no tratamento de patologias avançadas, mostra fragilidades quanto à sua instrumentalização por parte de ações humanas em pacientes nas UTIs. Entretanto, o CVC é um procedimento de grande importância, pois possibilita a realização da medicação de maneira mais segura por meio de infusão além da monitoração do pacientes. Importa-nos buscarmos um maior enquadramento quanto às medidas de controle dos IPCS. Essas medidas foram 
criadas pela ANVISA a fim de prevenir e, portanto, diminuir, senão eliminar, os quadros de infecções hospitalares. São medidas muito simples, mas importantes e contemplam a lavagem das mãos e higienização por meio de álcool gel a 70\%.

O presente artigo apontou que o efeito infeccioso pelo uso de cateter ocorre na corrente sanguínea, e, portanto, no momento da infusão, visto que ocorre a introdução de soluções no organismo do paciente. Importa que o sítio escolhido para infusão seja bem assepsiado, e, além do cateter, nesse contexto, pôde-se perceber elementos significantes na prevenção de infecções e, com isso, há o bem estar do paciente, o que concomitantemente acarreta a diminuição de gastos financeiros. Concluímos que as precauções de barreiras máximas não podem ser desprezadas, pois além do furtarse da utilização rotineira de antibióticos, a fim de neutralização colonização de microorganismos no cateter, essas precauções são instrumentos profícuos a todos os envolvidos no processo de UTIs em pacientes adultos.

Diante dos problemas apresentados no presente artigo, compreende-se que o CVC exige, também, maior preparo técnico e experiência do profissional da saúde além de regras de monitoramentos como o uso do Checklist. Nesse contexto, a tecnologia tem favorecido no desenvolvimento de equipamentos ambulatoriais sofisticados e profícuos aos tratamentos nas UTIs, e, também, as medidas protocolares quanto normatizações de higiene dos instrumentos (cateter), o manuseio por parte da equipe de enfermagem e a higienização do ambiente (UTI) e pacientes. Por fim, ações preventivas não podem ser de caráter apenas individual, mas devem envolver toda equipe hospitalar. Portanto, conceitos de ordem inter e multidisciplinar devem ser a tônica do processo preventivo nas UTls, cujo compromisso, respeito, companheirismo, organização e, acima de tudo, o respeito à vida é a máxima do profissionalismo de emergência hospitalar.

\section{REFERÊNCIAS}

BELO, M. P. M. et al. Neonatology nurses' knowledge about Peripherally Inserted Central Venous Catheter. Revista brasileira de enfermagem, v. 65, n. 1, p. 42-48, 2012. 
DALLÉ, J. et al. Infecção relacionada a cateter venoso central após a implementação de um conjunto de medidas preventivas (bundle) no centro de terapia intensiva (CTI) do Hospital de Clínicas de Porto Alegre. Revista HCPA, v. 32, n. 1, p. 10-17, 2012.

GOTTSCHALL, C. A. M. 1929-2009: 80 Years of cardiac catheterization-a history within history. Revista Brasileira de Cardiologia Invasiva, v. 17, n. 2, p. 246-268, 2009.

INOUE, K. C; MATSUDA, L. M. Dimensionamento da equipe de enfermagem da UTIadulto de um hospital ensino. Revista Eletrônica de Enfermagem, v. 11, n. 1, p. 5563, 2009.

NETTO, S. M. et al. Infecção de cateter vascular central em pacientes adultos de um centro de terapia intensiva. Revista gaúcha de enfermagem, v. 30, n. 3, p. 429-436, 2009.

PACHECO, G. C. et al. Conhecimento do Enfermeiro em Relação ao Cateter Totalmente Implantado. Journal of Health Sciences, v. 16, n. 3, p. 181-184, 2015.

PEDROLO, E. et al. Ensaio clínico controlado sobre o curativo de cateter venoso central. Acta Paulista de Enfermagem, v. 24, n. 2, p. 278-283, 2011.

SANTUZZI, C. H. et al. Aspectos éticos e humanizados da fisioterapia na UTI: uma revisão sistemática. Fisioterapia em Movimento, v. 26, n. 2, p. 415-422, 2013.

SILVA, J. A. de. J. S. Desfecho das complicações relacionadas ao uso de cateteres venosos centrais em Unidades de Terapia Intensiva. 2016. 69f. Dissertação (Mestrado em Enfermagem) - Universidade Federal do Triângulo Mineiro, Uberaba, 2016.

OLIVEIRA, F. T. de et al. Comportamento da equipe multiprofissional frente ao Bundle do Cateter Venoso Central na Terapia Intensiva. Escola Anna Nery Revista de Enfermagem, v. 20, n. 1, p. 55-62, 2016.

Enviado: Janeiro, 2020. 
Aprovado: Março, 2020. 